\title{
Caso clínico-radiológico pediátrico
}

\author{
JUAN OLIVOS P.* y CRISTIÁN GARCÍA B.**
}

\section{Pediatric clinical-radiological case}

\section{Historia clínica}

Paciente de sexo masculino de 11 años, sin antecedentes mórbidos conocidos, consulta en el Servicio de Urgencia por dolor torácico de 6 $\mathrm{h}$ de evolución, de inicio súbito luego de ingerir líquidos a baja temperatura, sin otros síntomas relevantes. A su ingreso no presenta alteraciones al examen físico y sus signos vitales eran normales para la edad.

Se solicitó electrocardiograma que resultó normal y una radiografía $(\mathrm{Rx})$ de tórax en proyecciones anteroposterior y lateral con el niño en posición de pie (Figura 1).

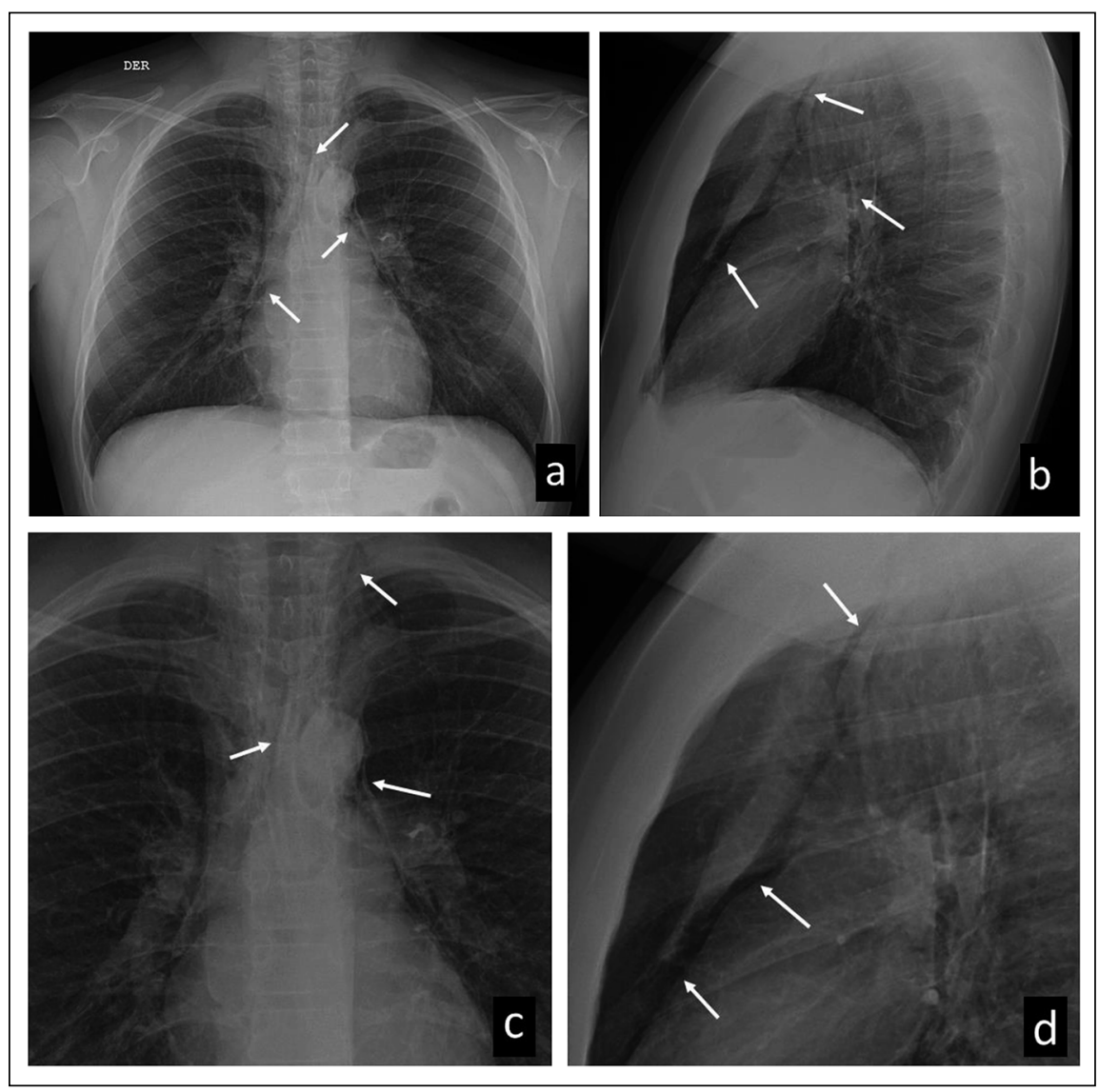

Figura 1. Rx de Tórax en proyecciones AP (a) y lateral (b) e imágenes magnificadas (c, d).

\section{¿Cuál es su diagnóstico?}

* Médico Radiólogo, Hospital Regional de Concepción. Concepción, Chile.

** Profesor Titular. Departamento de Radiología, Facultad de Medicina, Pontificia Universidad Católica de Chile. Santiago, Chile. 


\section{Hallazgos radiológicos}

La Rx de tórax (Figura 1) muestra imágenes lineales radiolúcidas que rodean el mediastino y se dirigen al cuello (flechas). En la proyección lateral, el timo está desplazado hacia anterior por aire (flechas).

Estos hallazgos descritos son característicos de un neumomediastino.

El examen se complementó con una Tomografía Computada de Tórax (Figura 2), que permite una mejor demostración anatómica del neumomediastino.

\section{Diagnóstico}

Neumomediastino espontáneo.

\section{Discusión}

El neumomediastino espontáneo (NME) fue descrito por Hamman (1939) en población adulta, bajo el nombre de "enfisema mediastínico espontáneo" $"$. Se define como la presencia de aire libre en el mediastino que aparece sin antecedentes de trauma torácico, procedimientos quirúrgicos de la vía aérea o digestiva, ventilación mecánica o cateterización ${ }^{2,3}$.

En población pediátrica la literatura es escasa, con una incidencia reportada de 1/8.000 a $1 / 15.000$ y dos peaks de edad observados entre 6 meses y 4 años y otro entre 15 y 18 años ${ }^{4,5}$. En adultos jóvenes la incidencia observada es mayor, de aproximadamente $1 / 800^{1,6}$.

En pediatría, el NME es más frecuente en el sexo masculino y un $60 \%$ ocurre en el período neonatal ${ }^{1,4}$. El asma es considerado el principal factor predisponente $(22 \%)$ y la sintomatología más frecuente es dolor torácico, dolor cervical, odinofagia, disnea, tos, dolor irradiado a la región dorsal $1^{1,2,7}$.

$\mathrm{Al}$ examen físico el principal hallazgo es generalmente enfisema subcutáneo en el cuello ${ }^{1,6,9}$. Los factores desencadenantes más frecuentes del NME son broncoespasmo, tos, infecciones respiratorias, acceso de vómitos, aspiración de cuerpo extraño, ejercicio físico o cualquier situación que induzca una maniobra de Valsalva ${ }^{1,4}$. En un $33 \%$ de los casos es idiopático ${ }^{1}$, como ocurrió en nuestro paciente.

El efecto Macklin, descrito en 1939, intenta explicar la fisiopatología de la fuga aérea en el $\mathrm{NME}^{5}$. Los gradientes de presión provocan ruptura alveolar, lo que condiciona a su vez escape aéreo al intersticio y linfáticos pulmonares (enfisema intersticial), el cual diseca a través de los septos interlobares adyacentes a los vasos sanguíneos y sistema bronquial hasta llegar al hilio y de ahí al mediastino y a otras regiones anatómicas ${ }^{1,3,5,8}$.

El enfrentamiento inicial debe ser hecho con radiografía $(\mathrm{Rx})$ de tórax en proyecciones anteroposterior (AP) y lateral, la que es suficiente para el diagnóstico hasta en $99 \%$ de los $\operatorname{casos}^{1,4,9}$. Los hallazgos dependerán de la cantidad de aire en el mediastino. Pueden observarse finas líneas radiolúcidas paralelas al borde del mediastino en la proyección AP y lateral, elevación del timo, delimitación del cayado aórtico. También puede detectarse el signo del diafragma continuo, producido por la interposición de aire entre el corazón y el diafragma. Esto no debe confundirse con neumopericardio donde generalmente se visualiza el aire dentro del saco pericárdico y

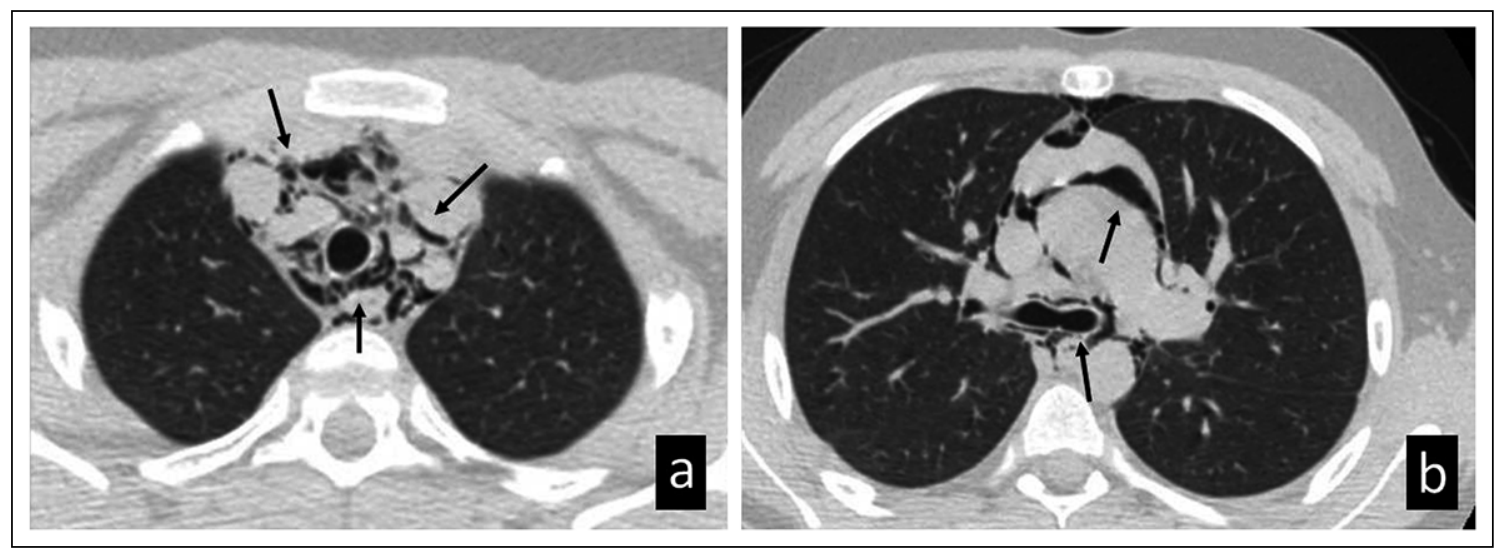

Figura 2. Tomografía Computada de Tórax con medio de contraste endovenoso y cortes axiales a nivel de los vasos supraaórticos (a) y del tronco de la arteria pulmonar (b) muestra extenso aire extraalveolar que diseca los distintos planos del mediastino (flechas). 
aparece como una imagen radiolúcida que rodea el corazón. También debe diferenciarse de un neumotórax medial. Tanto el neumopericardio como el neumotórax, pueden coexistir con el neumomediastino.

La presencia de enfisema en las partes blandas del cuello en la Rx apoya fuertemente el diagnóstico de neumomediastino.

El NME presenta una evolución generalmente benigna y en la mayor parte de los casos se resuelve espontáneamente y el tratamiento puede ser ambulatorio, pero según su cuantía y sintomatología, puede requerir hospitalización ${ }^{3}$. Se maneja con reposo, tratamiento del factor predisponente, si éste es identificado, administración de oxígeno, analgésicos y la Rx de tórax generalmente es normal en controles alejados ${ }^{1,3}$. La recurrencia es muy infrecuente.

Si bien es una patología poco frecuente, el NME debe ser considerado en el diagnóstico diferencial de dolor torácico agudo en niños y adolescentes.

\section{Bibliografía}

1.- GASSER CRB, PELLATON R, ROCHAT CP. Pediatric Spontaneous Pneumomediastinum: Narrative Literature Review. Ped emergency care 2017; 33: 370-4.
2.- ÁLVAREZ C, JADUE A, ROJAS F, CERDA C, RAMÍREZ M, CORNEJO C. Neumomediastino espontáneo (Síndrome de Hamman): Una enfermedad benigna mal diagnosticada. Rev Med Chile 2009; 137: 1045-50.

3.- CHALUMEAU M, LE CLAINCHE L, SAYEG N, SANNIER N, MICHEL JL, MARIANOWSKI R, et al. Spontaneous pneumomediastinum in children. Pediatr Pulmonol 2001; 31: 67-75.

4.- CHEN IC, TSENG CM, HSU JH, WU JR, DAI ZK. Spontaneous pneumomediastinum in Adolescents and Children. The Kaohsiung J of Med Sciences 2010; 26: 84-8.

5.- MURAYAMA S, GIBO S. Spontaneous pneumomediastinum and Macklin effect: Overview and appearance on computed tomography. World J Radiol 2014; 28: 850-4.

6.- LEE CY, WU CC, LIN CY. Etiologies of spontaneous pneumomediastinum in children of different ages. Pediatr Neonatol 2009; 50: 190-5.

7.- CHAPDELAINE J, BEAUNOYER M, DAIGNEAULT P, BÉRUBÉ D, BÜTTER A, OUIMET A, et al. Spontaneous pneumomediastinum: are we overinvestigating? J Pediatr Surg 2004; 39: 681-4.

8.- CHIU CY, WONG KS, YAO TC, HUANG JL. Asthmatic versus non-asthmatic spontaneous pneumomediastinum in children. Asian Pac J Allergy Immunol 2005; 23: 19-22.

9.- ZYLAK CM, STANDEN JR, BARNES GR, ZYLAK CJ. Pneumomediastinum Revisited. Radio Graphics 2000; 20: 1043-57.
Correspondencia a:

Dr. Cristián García B.

Departamento de Radiología, Facultad de Medicina,

Pontificia Universidad Católica de Chile.

Email: cgarcia@med.puc.cl 